\title{
A case study on teachers assistance in writing classroom: a look at the effects on rural learners writing self-efficacy
}

\begin{abstract}
Overall, this study aims to explore three rural area learners' writing self-efficacy after certain amount of assistance given by the teacher. The specific objective is to investigate the effect of the teacher's assistance on the rural students' writing self-efficacy. Thus, this study places a heavy emphasis on the perceptions and actions of three Form Four students and a teacher within five-month non-participant classroom observations, and interviews with each of the three students and the teacher after each observation. In order to determine the development of the students' writing self-efficacy level after assistances were provided, two different techniques were used. Firstly, the learners' writing self-efficacy was evaluated using writing self-efficacy scale and classroom observation. The writing self-efficacy scale was adapted from Bottomley, Henk \& Melnick (1998) which provides the researchers with the descriptive statistics such as mean and overall scores in order to describe the level of the students' writing self-efficacy. Secondly, this study also adopted classroom observation using the guidelines adapted from Wang \& Pape (2007) for analysing self-efficacy to understand the participants' self-efficacy phenomena in their learning to write. These evidences of the learner's self-efficacy beliefs were classified into three categories: i) persistence in accomplishing language tasks, ii) self-awareness of English proficiency, iii) willingness to engage in language activities. The findings showed the teacher adopted a writing process approach to teach writing and provided five different assistances via the process. The average and high-efficacy writers increased their writing self-efficacy when the teacher provided direct assistance. Nevertheless, one low self-efficacy writer was found to withdraw from the task and demotivated when direct assistance was provided. The low self-efficacy writer only felt confident to write when written comments were given. The findings imply that learners' writing self-efficacy changed depending on the assistance given. Thus, it is important for the teacher to consider learners' writing self-efficacy in teaching writing. In addition, with the combination of qualitative and quantitative methods in analysing self-efficacy, it thus portrayed a more feasible way in exploring a self-efficacy development.
\end{abstract}

Keyword: Writing self-efficacy; Teachers assistance; Rural area learners 